\title{
A Study on the Environmental Education and Compulsory Education Equalization Issue-A case study of Shandong Province
}

\author{
Xili YANG \\ College of Vocational Education (Yishui Campus) of Linyi University, 1 Culture Road of Yishui County \\ Shandong Province, China \\ e-mail: ccivylily@163.com
}

\begin{abstract}
Environmental education is a type of education activity which takes the relationship between human beings and the environment as the core. This article takes Shandong province as an example to carry out environmental education and compulsory education equalization issue research, combine environmental education with compulsory education, analyze equal education development countermeasures and provide some suggestions. Questionnaire showed that the environmental education have some problems, such as environmental consciousness lag, the lack of the knowledge of environmental protection, the shortage of teachers on environmental education and fewer environment education methods. we should draw lessons from the abroad and strengthen the implementation of laws and regulations, perfect the effective security system and the construction of evaluation system, perfect the education of the public finance system, perfect the education funds supervision and audit system, accelerate the construction of environmental education and integrate of urban and rural education information, so as to promote the all-round development of primary and middle school environment education and compulsory education, promote environmental awareness, to lay a good foundation for the control of environmental pollution and human health protection.
\end{abstract}

Keywords-environmental education equal compulsory; education; environmental pollution

\section{INTRODUCTION}

With the rapid economic and social development, a lot of resources are consumed, waste water, waste gas, a large amount of waste residue led to further deterioration of the environment, haze, acid rain and other environmental pollution has seriously affected the survival and development of human beings. Environmental pollution prevention and environment protection have become social issues of common concern[1]. At the same time, the human concern about the deterioration of living environment makes environmental education come into being. Its original motive comes from human care and cherishing of his life. The so-called environmental education considers the relationship between mankind and the environment as the core, in order to solve environmental problems and achieve sustainable development for the purpose of improving people's environmental awareness and effective participation, universal environmental protection knowledge and skills, training environmental protection personnel for the task, and to educate as a means to start a social practice process[2]. In April 1986, China promulgated the "Compulsory Education Law of the People's Republic of China". As an important basic project of rejuvenating the nation through science and education, compulsory education can improve the overall quality of the Chinese nation, and promote the process of modernization. With global guidance and the role of foundation and guarantee, this will largely accelerate the construction of a harmonious society.

This paper takes Shandong Province as an example to study the issues of equalization of environmental education and compulsory education, combine environmental education with compulsory education, and promote the equalization of education development, in order to establish the foundation of fully improving the environmental awareness.

\section{THE STATUS OF ENVIRONMENTAL EDUCATION AND EQUAL COMPULSORY EDUCATION DEVELOPMENT IN}

\section{SHANDONG PROVINCE}

\section{A. Current Situation and Problems of Environmental Education in Shandong Province}

Questionnaires results came from 20 secondary schools and 50 primary schools which has involved 200 students and teachers in Shandong province. There are several serious problems in the environmental education of Shandong province which include lag in the awareness of the environmental education, lack of environmental protection knowledge, shortage of environmental education teachers, and so on[2].

First of all, lag in the awareness of the environmental education. In the investigation, the author found that the current human society is generally facing a series of environmental problems such as air pollution, climate warming, freshwater exhausting, forest declining sharply, land desertification, species extinction, the ozone layer loss and so on, which fail to draw the attention from the teachers and students of primary and secondary schools. The vast majority of people in the surveyed 200 students are lack of adequate knowledge about the severity and harmfulness of environmental pollution. Thus, no matter for schools, teachers or students, the awareness of environmental education is obviously lagging.

Secondly, lack of environmental protection knowledge. According to the survey, the author found that primary and 
secondary school teachers can not explain clearly the common environmental pollution case such as ozone layer depleting, soil acidification, greenhouse effect. 38 out of the 80 teachers surveyed had not heard of these words. When I asked the students to write several kinds of familiar names of environmental pollution, the result is that only 30 out of 120 surveyed students could answer better.

Thirdly, shortage of environmental education teachers. According to the investigation, there is no full-time teacher in environmental protection teaching in these 50 primary and secondary schools. The speakers of three primary schools which have hold one-time environment education project is technical personnel of local environmental protection department.

The causes of the above phenomenon are both subjective factors of the education departments and school teachers ignoring of environmental education, and the objective factors of the relatively inferior teaching material and the lack of data in these primary and secondary schools, and having not formed the climate of environment education.

\section{B. Compulsory Education Equalization Problem}

In recent years, Shandong province is actively exploring actively, and equal compulsory education development pilot work has accomplished remarkable achievements. In general, promoting the equal compulsory education development still faces some difficulties and challenges[3].

a. The uneven spending of nine-year compulsory education completion and urban and rural primary and secondary school education

From the perspective of levels, early childhood education and the popularization of high school education and the perfection of the relevant terms of the education are the weak links. From the perspective of students, trailing children of migrant workers, left-behind children, children in poor families, and physically handicapped students are becoming more and more prominent. Take the gap between urban and rural areas as an example, ordinary junior high school in Shandong province in 2010 embraced non-profit-making expenditure of $5688.87 \mathrm{RMB}$ per student, while that of the rural area is 5369.03. The difference is $319.84 \mathrm{RMB}$. The non-profit-making expenditure in Ordinary primary schools is 3571.76 RMB per student, while that of the rural area is 3388.25. The difference is $183.51 \mathrm{RMB}$,

b. The insufficient of the amount of education investment

The financing channels cutting of education investment in Shandong province led to the shortage of the amount of education funds investment. The education budget investment of Shandong province is 41.173 billion RMB in 2009 and is higher than that of 2008 by $25.48 \%$. However, it is still lower than the proportion $31.93 \%$ of the national average growth. In 2009, the education funds of Shandong province accounted for $22.79 \%$ of the budget spending.

c. The development of urban and rural compulsory education equalization presenting complexity

Development of urban and rural compulsory education equalization presented new features, the complexity. One is the city workers trailing children problems. With the increase of rural migrant workers, the size of their children's trailing is also increasing. Second is the left-behind children problem. Due to the increase of rural migrant workers, the number of left-behind children is constantly increasing. Since most left-behind children are scattering in rural areas, their living and studying conditions are tough. Third is the issue of school choice. Because of school difference, regional disparity and urban-rural gap, the issue of school choice is still in the cities and schools which have high level of compulsory education resources and conditions.

\section{The PRACTICE OF THE EQUALITY OF THE} SUCCESSFUL EXPERIENCE OF ENVIRONMENTAL EDUCATION AND COMPULSORY EDUCATION ABROAD

The concept of "equalization" in the education field started late in China, the environment education and equal compulsory education is lagged behind. Therefore, it is necessary to draw lessons from foreign advanced countries in the practice and development experience of the compulsory education (its called "basic education" in foreign education), brought strong inspiration for equalization of compulsory education in China, to promote the development of the equal of urban and rural compulsory education in China more effectively[4].

\section{A. Strong Legal Protection and Policy Support}

The English Central Education Advisory Committee published The Plowden Report in 1967, this is the beginning of Britain to adopt a policy of "education priority area", the policy is based on the parents' occupation, family situation, student's basic situation to determine which area is education priority area, and how much education bonus is for these areas. By implementing this policy, not only effectively reduce the compulsory education in urban and rural differences and regional differences, but also to ensure the effective implementation of compulsory education equality of opportunity.

\section{B. Strong Financial Support and System Support}

From the experience around the world, all countries that have equal environment education and compulsory education development value and ensure the investment of environmental education and compulsory education, and the importance is enlarging, the proportion of investment is increasing in the promoting of equal development in the United States, we can fully see the difference of various areas, types and schools. The United States has adopted some institutions such as "free choice on education" and education voucher.

\section{The Flexible Flow Mechanism of Teachers}

In order to obtain the balanced development of different schools in Japan, it applied the teachers' regular exchange system. This kind of exchange is done in the same county or same city; each teacher generally exchanged every three to five years in the school, teachers' treatment did not change due to changing schools. The United States attaches great 
importance to environmental education and the teacher's professional quality, not only establish a set of measure to test whether the teachers' quality qualified professional standards, but set up a relatively independent professional standards committee.

\section{THE SPECIFIC COUNTERMEASURES AND} SUGGESTIONS OF EQUALIZATION OF ENVIRONMENTAL EDUCATION AND COMPULSORY EDUCATION

Firstly, strengthen the implementation of relevant laws and regulations of environmental education and urban and rural compulsory education.In the form of law to the environmental education and urban and rural compulsory education equalization development of the policies, systems and specific measures, etc., fixed down in the long-term. Therefore, we should make sure that in the specific process of equal development there are laws to follow.

Secondly, improve the equalization of the environmental education and compulsory education in urban and rural areas to ensure the effective protection of the system and the construction of evaluation system. Education department of Shandong province should promote the equalization development of environmental education and urban and rural compulsory education, specifically establish the monitoring and evaluation system to the government, and strengthen the assessment. We should monitor and supervise the environmental education and compulsory education equalization development level, especially strengthen the supervision of the education process, in order to discover and solve problems, timely publicize of monitoring and evaluation results, and put the results into the government performance evaluation system.

Thirdly, improve the public finance system of environmental education and compulsory education. In the current and future period of time, the development goal of China's compulsory education is to ensure that our every school-age children and adolescents, not restricted by any conditions, are able to successfully complete nine years of free compulsory education and enjoy the right to education. According to its economic development and financial strength, to a certain extent, the government has reduced the primary and secondary school fees, only collecting textbook fees, increased public financial investment, to realize the publicity and education of environmental protection.

Fourthly, establish and improve the supervision and audit system of environmental education and compulsory education funds. In order to guarantee the environmental education and compulsory education funds to be used reasonably and scientifically, we must establish and improve the effective supervision system and the strict auditing system of environmental education and compulsory education funds. The allocation and use of the fund for environment education and compulsory education must be placed under public supervision, be supervised and audited fairly and strictly. The auditing should be led by national auditing system, insist on the close combination among school internal audit, national sector audit, social third-party audit, and firmly ensure that the audit process is open, fair and equitable.

\section{REFERENCES}

[1] Xiaoping, Zhou. The Core Concepts and Objectives of Environmental Education [J]. College Journal of Beijing Normal University (Social Science Version), 2002(3):118-122.

[2] Xisheng, Huang, Lingzhi, Zhang. Study on the Current Situation and Countermeasures of Environmental Education in China [J]. College Journal of Chongqing University (Social Science Version), 200511(4):134-137.

[3] Shijun, Ren., Yanxia, Sun. Study on the Development Forecast of Compulsory Education [J]. Educational Science, 2005, (6):10-13.

[4] Yuling, Yin. The Initiatives and Enlightenment of Promoting the Balancing Development of Basic Education in United States [J]. Shanghai Education Research and Development, 2005(12)27-28. 